\title{
Efficacy and safety of intrathecal meropenem and vancomycin in the treatment of postoperative intracranial infection in patients with severe traumatic brain injury
}

\author{
QIANG ZHANG ${ }^{1}, \mathrm{HONGXING} \mathrm{CHEN}^{2}, \mathrm{CHAO} \mathrm{ZHU}^{3}$, FANGZHOU CHEN $^{3}$, \\ SUOHUI SUN ${ }^{3}$, NAN LIANG ${ }^{3}$ and WEI ZHENG ${ }^{3}$ \\ ${ }^{1}$ Emergency Department, Tai'an Traditional Chinese Medicine Hospital; \\ Departments of ${ }^{2}$ ICU and ${ }^{3}$ Neurosurgery, Affiliated Hospital of Taishan Medical University, \\ Tai'an, Shandong 271000, P.R. China
}

Received November 27, 2018; Accepted April 5, 2019

DOI: $10.3892 /$ etm.2019.7503

\begin{abstract}
This study investigated the improvement and safety of intrathecal meropenem and vancomycin in the treatment of postoperative intracranial infection in patients with severe traumatic brain injury (STBI). A retrospective analysis was performed on 86 patients with intracranial infections after cranial trauma operation in Tai'an Traditional Chinese Medicine Hospital and Affiliated Hospital of Taishan Medical University from May 2004 to June 2017. The patients were divided into the control group (43 patients) and the experimental group (43 patients) according to the treatment. Patients in the control group were intravenously infused with vancomycin hydrochloride $(1.0 \mathrm{~g}, \mathrm{Q} 12 \mathrm{H})$ and meropenem $(2.0 \mathrm{~g}$, $\mathrm{Q} 8 \mathrm{H})$. After lumbar cistern drainage was performed for the release of cerebrospinal fluid (CSF), patients in the experimental group were slowly given vancomycin $20 \mathrm{mg}$. After the tube was flushed with $2 \mathrm{ml}$ of $0.9 \%$ sodium chloride injection, the patients were slowly given meropenem $20 \mathrm{mg}$, bid. The clinical efficacy, cure time and treatment cost of patients in the two groups were observed. The adverse reactions and sequelae after 6 months of treatment were recorded. The response rate $(\mathrm{RR})$ of patients in the experimental group was significantly higher than that in the control group $(\mathrm{P}<0.05)$. The cure time of patients in the experimental group was significantly lower than that in the control group $(\mathrm{P}<0.05)$. The treatment cost of patients in the experimental group was significantly lower than that in the control group $(\mathrm{P}<0.05)$. The incidence of adverse reactions of patients, incidence of sequelae of patients in the experimental group was significantly lower than that
\end{abstract}

Correspondence to: Dr Wei Zheng, Department of Neurosurgery, Affiliated Hospital of Taishan Medical University, 366 Taishan Avenue, Tai'an, Shandong 271000, P.R. China

E-mail:vvt26t@163.com

Key words: intrathecal injection, meropenem, vancomycin, severe traumatic brain injury, efficacy, safety in the control group $(\mathrm{P}<0.05)$. Intrathecal meropenem and vancomycin is more effective than intravenous administration in the treatment of intracranial infection after craniotomy. It can significantly shorten the treatment time and reduce the treatment cost, with better safety.

\section{Introduction}

As the economy develops and vehicles become more and more common, the incidence of car accidents is constantly increasing, and that of traumatic brain injury (TBI) is also increasing. Severe traumatic brain injury (STBI) is an acute and severe disease that is common, with rapid progression and complicated conditions. After the patient is injured, there will be energy metabolism disturbance, hypoxia, apoptosis and massive release of oxygen free radicals in the body, which cause different necrosis and degeneration of the tissue $(1,2)$. Studies have shown that $(3,4)$ the progression of STBI is related to vascular permeability and inflammatory factor release. There is a study showing that (5) patients with STBI produce a large number of inflammatory mediators under long-term pathological stress, thereby leading the body into an inflammatory state and further aggravating the condition. Cerebrospinal fluid (CSF) is a rich medium in which inflammation is rapidly transmitted to the central nervous system through a series of events when an intracranial infection occurs. Intracranial infection has been treated in recent years by lumbar cistern drainage and broad-spectrum antimicrobial drugs. Vancomycin has been widely used in the treatment of intracranial infection (6) and is highly sensitive to Gram-positive bacteria, such as staphylococcus aureus and staphylococcus epidermidis. Meropenem is one of the semi-synthetic carbapenem antibacterial agents, the sensitivity of which to Gram-negative bacteria is up to $95 \%$. The treatment safety and efficacy of intracranial infection has been confirmed (7). Intravenous injection is difficult to pass the blood-brain barrier, which results in severe intracranial infection, eventually causing the treatment to be more difficult with unsatisfactory effects. Therefore, other routes of administration are often selected clinically to reduce intravenous 
administration. Intrathecal injection is a treatment that is administered directly to the patient's CSF through lumbar puncture. Whether it can improve the efficacy and safety has also attracted the attention of scholars. In this study, the efficacy and safety of intrathecal meropenem and vancomycin in the treatment of postoperative intracranial infection in patients with STBI were investigated, in order to provide a reference for future clinical treatment.

\section{Materials and methods}

General information. A retrospective analysis was performed on 86 patients with intracranial infections after cranial trauma operation in Tai'an Traditional Chinese Medicine Hospital and Affiliated Hospital of Taishan Medical University (Tai'an, China) from May 2004 to June 2017. The patients were divided into the control group (43 patients) and the experimental group (43 patients) according to the treatment. The experimental group consisted of 22 males and 21 females with an age range of 30.01 \pm 9.04 years. The control group consisted of 24 males and 19 females with an age range of $29.73 \pm 10.37$ years. There were no statistically significant differences in the sex, age, body weight and cause of injury of patients between the two groups $(\mathrm{P}>0.05)$, which were comparable (Table I).

Methods. Patients in the two groups were routinely treated with antibiotics to prevent infection after craniotomy. After being diagnosed with intracranial infection, lumbar cistern drainage was performed on patients in the control group for the release of CSF, and then the patients were given vancomycin hydrochloride injection (Zhejiang Pharmaceutical Co., Ltd.; Xinchang Pharmaceutical Factory, Zhejiang, China; guoyaozhunzi: H20033366) $1.0 \mathrm{~g}$, ivgtt, Q12H and intravenously dripped meropenem (Sumitomo Pharmaceutical Suzhou Co., Ltd., Suzhou, China; guoyaozhunzi: J20140169) $2.0 \mathrm{~g}$, ivgtt, Q8H. Lumbar cistern drainage was performed on patients in the experimental group for the release of CSF, and then the patients were slowly given $20 \mathrm{mg}$ of vancomycin hydrochloride injection. After the tube was flushed with $2 \mathrm{ml}$ of $0.9 \%$ sodium chloride injection, the patients in the experimental group were given meropenem intrathecal injection $20 \mathrm{mg}$, bid. Patients in both groups were treated for 2 weeks.

Inclusion and exclusion criteria. Inclusion criteria were: Patients who were diagnosed with STBI after admission; patients with Glasgow Coma Scale (GCS) scores between 3 and 8 points; patients with mydriasis. Exclusion criteria were: Patients with contraindications for vancomycin and meropenem; patients with uncertain conditions; patients with shock and fractures.

The study was approved by the Ethics Committee of Tai'an Traditional Chinese Medicine Hospital and Affiliated Hospital of Taishan Medical University. Patients and their families were informed in advance of the study, and signed an informed consent form.

Observation indicators and outcome measures. Observation indicators: The clinical efficacy, cure time, treatment cost, adverse reactions and sequelae after 6 months of treatment of patients in the two groups.
Outcome measures were: Recovered: Symptoms and signs disappeared and CSF examination was normal; markedly effective: the observation indicators were not fully recovered but the condition was improved; invalid: The condition deteriorated or was not improved after $72 \mathrm{~h}$ of treatment. Response rate $(\mathrm{RR})=$ (number of recovered cases + number of markedly effective cases)/total number of cases $\times 100 \%$.

Statistical analysis. SPSS 17.0 (Beijing Boyi Zhixun Information Technology Co., Ltd., Beijing, China) software system was used for statistical analysis. Enumeration data were expressed as [n (\%)], and $\chi^{2}$ test was used for comparison between the two groups. Students' t-test was used for comparison between the two groups for continuous data. At $\mathrm{P}<0.05$, the difference was considered statistically significant.

\section{Results}

Clinical efficacy of patients in the two groups. There were 22 recovered patients, 19 markedly effective patients and 2 invalid patients in the experimental group, with an RR of $95.35 \%$. There were 15 recovered patients, 16 markedly effective patients and 12 invalid patients in the control group, with an RR of $72.09 \%$. The RR of patients in the experimental group was significantly higher than that in the control group, with a statistically significant difference $(\mathrm{P}<0.05)$ (Table II).

The cure time and treatment cost of patients in the two groups. The cure time and treatment cost of patients in the control group were $23 \pm 9$ days and $2.6 \pm 1.2$ yuan, respectively. Those of patients in the experimental group were $11 \pm 5$ days and $1.8 \pm 0.7$ yuan, respectively. The time to cure of patients in the experimental group was significantly shorter than that in the control group, with a statistically significant difference $(\mathrm{t}=7.643, \mathrm{P}<0.001)$. The treatment cost of patients in the experimental group was significantly lower than that in the control group, with a statistically significant difference $(\mathrm{t}=3.776, \mathrm{P}<0.001)$ (Figs. 1 and 2).

Adverse reaction records of patients in the two groups. There was 1 patient with diarrhea, 1 patient with swelling and pain in the injection site and 1 patient with nausea in the experimental group, with an incidence of $6.98 \%$. There were 2 patients with diarrhea, 4 patients with swelling and pain in the injection site and 4 patients with nausea in the control group, with the incidence of $23.26 \%$. The incidence of adverse reactions of patients in the experimental group was significantly lower than that in the control group, with a statistically significant difference $(\mathrm{P}<0.05)$ (Table III).

Sequelae of patients after 6 months of treatment in the two groups. After 6 months of treatment, there was no patient with auditory nerve abnormalities, 1 patient with motor nerve abnormalities and no patient with epilepsy in the experimental group, with the incidence of sequelae of $2.33 \%$. There were 3 patients with auditory nerve abnormalities, 4 patients with motor nerve abnormalities and 2 patients with epilepsy in the control group, with the incidence of sequelae of $20.93 \%$. The incidence of sequelae of patients in the experimental group was significantly lower than that in the control group, with a statistically significant difference $(\mathrm{P}<0.05)$ (Table IV). 
Table I. General information of patients in the two groups [n (\%)].

\begin{tabular}{|c|c|c|c|c|}
\hline Group & Experimental group $(n=43)$ & Control group $(n=43)$ & $\chi^{2}$ test & P-value \\
\hline \multicolumn{5}{|l|}{ Sex } \\
\hline Male & $22(51.16)$ & $24(55.81)$ & 0.187 & 0.666 \\
\hline Female & $21(48.84)$ & $19(44.19)$ & & \\
\hline \multicolumn{5}{|l|}{ Age (years) } \\
\hline$<30$ & $17(39.53)$ & $16(37.21)$ & 0.049 & 0.825 \\
\hline$\geq 30$ & $26(60.47)$ & $27(62.79)$ & & \\
\hline \multicolumn{5}{|l|}{ Body weight } \\
\hline$<55$ & $15(34.88)$ & $13(30.23)$ & 0.212 & 0.645 \\
\hline$\geq 55$ & $28(65.12)$ & $30(69.77)$ & & \\
\hline \multicolumn{5}{|l|}{ Cause of injury } \\
\hline Falling down & $11(25.58)$ & $9(20.93)$ & 1.408 & 0.704 \\
\hline Traffic accident & $8(18.60)$ & $12(27.91)$ & & \\
\hline Dropping & $14(32.56)$ & $11(25.58)$ & & \\
\hline Industrial accident & $10(23.26)$ & $11(25.58)$ & & \\
\hline
\end{tabular}

Table II. The clinical efficacy of patients in the two groups [n (\%)].

\begin{tabular}{|c|c|c|c|c|}
\hline Group & Recovered & Markedly effective & Invalid & $\mathrm{RR}$ \\
\hline Experimental group $(n=43)$ & $22(51.16)$ & 19 (44.19) & $2(4.65)$ & $41(95.35)$ \\
\hline Control group $(n=43)$ & $15(34.88)$ & $16(37.21)$ & $12(27.91)$ & $31(72.09)$ \\
\hline$\chi^{2}$ test & - & - & - & 8.532 \\
\hline P-value & - & - & - & 0.004 \\
\hline
\end{tabular}

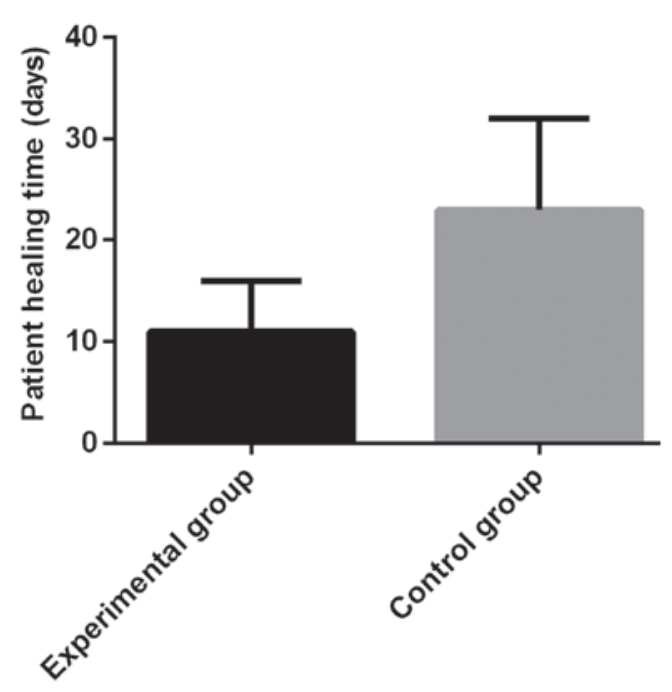

Figure 1. Comparison of the time to cure of patients between the two groups. The time to cure of patients in the experimental group was significantly shorter than that in the control group, with a statistically significant difference $(\mathrm{P}<0.001)$.

\section{Discussion}

TBI refers to a common trauma and is divided into light, moderate, heavy and extra-heavy traumas according to severity. Often accompanied by epilepsy, infection and

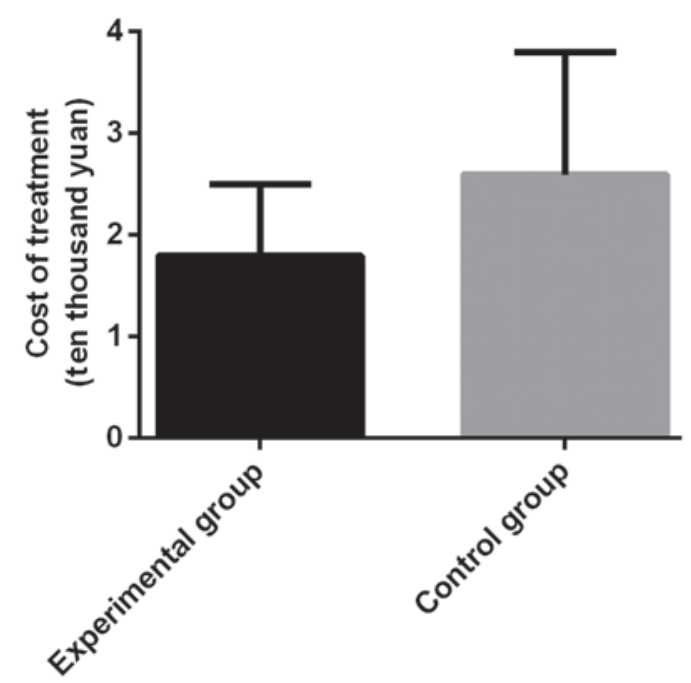

Figure 2. Comparison of the treatment cost of patients between the two groups. The treatment cost of patients in the experimental group was significantly lower than that in the control group, with a statistically significant difference $(\mathrm{P}<0.001)$.

cerebral infarction, which even causes coma in patients with serious TBI $(8,9)$. The mortality of TBI has been significantly reduced in recent years with the improvement of medical technology. However, due to the nerve function injury of patients, its disability rate remains high $(10,11)$. Patients with STBI 
Table III. Adverse reaction records of patients in the two groups [n (\%)].

\begin{tabular}{lcccc}
\hline Group & Diarrhea & $\begin{array}{c}\text { Swelling and pain in } \\
\text { the injection site }\end{array}$ & Nausea & Incidence \\
\hline Experimental group $(\mathrm{n}=43)$ & $1(2.33)$ & $1(2.33)$ & $1(2.33)$ & $3(6.98)$ \\
Control group $(\mathrm{n}=43)$ & $2(4.65)$ & $4(9.30)$ & $4(9.30)$ & $10(23.26)$ \\
$\chi^{2}$ test & - & - & - & 4.440 \\
P-value & - & - & - & 0.035 \\
\hline
\end{tabular}

Table IV. Sequelae of patients after 6 months of treatment in the two groups [n (\%)].

\begin{tabular}{lcccc}
\hline Group & $\begin{array}{c}\text { Auditory nerve } \\
\text { abnormalities }\end{array}$ & $\begin{array}{c}\text { Motor nerve } \\
\text { abnormalities }\end{array}$ & Epilepsy & Total incidence \\
\hline Experimental group $(\mathrm{n}=43)$ & $0(0)$ & $1(2.33)$ & $0(0)$ & $1(2.33)$ \\
Control group $(\mathrm{n}=43)$ & $3(6.98)$ & $4(9.30)$ & $2(4.65)$ & $9(20.93)$ \\
$\chi^{2}$ test & - & - & - & 7.242 \\
P-value & - & - & - & 0.007 \\
\hline
\end{tabular}

are critically ill and often affected by increased intracranial pressure and toxic metabolites, resulting in sustained brain injury $(12,13)$. Intracranial infection, one of the complications of cranial operation, is treated with the complete elimination of surgical infected wounds, with antibiotic, symptomatic and supportive treatments (14). Intracranial infection usually occurs within 3-7 days after cranial operation (15), accompanied by fever, disturbance of consciousness and other clinical manifestations. Postoperative intracranial infection poses a serious threat to the patient's life and requires timely action (16). Intracranial infection refers to a disease caused by viruses and bacteria, especially for patients undergoing neurosurgery operation. It has a $10-25 \%$ infection rate, and a high mortality and disability rate (17-19). Therefore, optimizing STBI is of great significance. It is necessary to improve the prognosis of the patient, as well as reduce the cure time, hospitalization cost and incidence of complications in order to improve the quality of life and prognosis of the patient.

The efficacy was first compared in this experiment. The results showed that the RR of patients in the experimental group was significantly higher than that in the control group, with a statistically significant difference $(\mathrm{P}<0.05)$. There is a study showing that (20) intravenous meropenem and vancomycin has a long cure time and high treatment cost, which also affects the liver and kidney function of the patient. At present, the use of intrathecal drugs has attracted much attention (21). Studies have confirmed $(22,23)$ that intrathecal vancomycin and meropenem has good clinical efficacy. This is similar to the results of this study. Then, the cure time and treatment cost of patients were compared between the two groups. The results showed that the cure time of patients in the experimental group was significantly lower than that in the control group, with a statistically significant difference $(\mathrm{P}<0.001)$. The treatment cost of patients in the experimental group was significantly lower than that in the control group, with a statistically significant difference $(\mathrm{P}<0.001)$. A study shows that $(24)$ intrathecal meropenem and vancomycin is more effective than intravenous meropenem and vancomycin in the treatment of postoperative infection, which shortens the treatment time and reduces the treatment cost. Next, the adverse reactions of patients in the two groups were compared. The results showed that the incidence of adverse reactions of patients in the experimental group was significantly lower than that in the control group, with a statistically significant difference $(\mathrm{P}<0.05)$. Finally, the sequelae of patients after 6 months of treatment were compared. The results showed that the incidence of sequelae of patients in the experimental group was significantly lower than that in the control group, with a statistically significant difference $(\mathrm{P}<0.05)$. There is a study suggesting $(25)$ that continuous lumbar drainage allows the CSF to drain continuously and slowly through the drainage tube, as well as reduces pathogenic microorganisms and inflammatory factors in the subarachnoid space so as to replace the CSF. In addition, intrathecal administration through the lumbar cistern reduces the incidence of adverse reactions and complications. The present study is an excellent complement to the results of that paper.

The number of patients included in this study is not large enough for conclusive statistics, so certain limitations exist and further investigations are required.

In summary, intrathecal meropenem and vancomycin is more effective than intravenous injection in the treatment of intracranial infection after craniotomy. It can shorten the treatment time and reduce the treatment cost, and is safer and has less adverse reactions and fewer complications.

\section{Acknowledgements}

Not applicable.

\section{Funding}

No funding was received. 


\section{Availability of data and materials}

The datasets used and/or analyzed during the present study are available from the corresponding author on reasonable request.

\section{Authors' contributions}

QZ wrote the manuscript. QZ and $\mathrm{HC}$ were responsible for observation indicators. CZ collected the patient data. FC analyzed and interpreted the patient general data with severe traumatic brain injury. SS and NL contributed to outcome measures. QZ and WZ helped with statistical analysis. All authors read and approved the final manuscript.

\section{Ethics approval and consent to participate}

The study was approved by the Ethics Committee of Tai'an Traditional Chinese Medicine Hospital and Affiliated Hospital of Taishan Medical University (Tai'an, China). Patients who participated in this study had complete clinical data. Signed informed consents were obtained from the patients or the guardians.

\section{Patient consent for publication}

Not applicable.

\section{Competing interests}

The authors declare that they have no competing interests.

\section{References}

1. Gupta MK, Mondkar JA and Hegde D: Paradoxical reaction to midazolam in preterm neonates: A case series. Indian J Crit Care Med 22: 300-302, 2018.

2. Dey S and Kumar M: Comparison of pretreatment with dexmedetomidine with midazolam for prevention of etomidate-induced myoclonus and attenuation of stress response at intubation: A randomized controlled study. J Anaesthesiol Clin Pharmacol 34: 94-98, 2018.

3. Paleti S, Prasad PK and Lakshmi BS: A randomized clinical trial of intrathecal magnesium sulfate versus midazolam with epidural administration of $0.75 \%$ ropivacaine for patients with preeclampsia scheduled for elective cesarean section. J Anaesthesiol Clin Pharmacol 34: 23-28, 2018.

4. Azeem TM, Yosif NE, Alansary AM, Esmat IM and Mohamed AK: Dexmedetomidine vs morphine and midazolam in the prevention and treatment of delirium after adult cardiac surgery; a randomized, double-blinded clinical trial. Saudi J Anaesth 12: 190-197, 2018.

5. Mazzeo AT, Filippini C, Rosato R, Fanelli V, Assenzio B, Piper I, Howells T, Mastromauro I, Berardino M, Ducati A, et al: Multivariate projection method to investigate inflammation associated with secondary insults and outcome after human traumatic brain injury: A pilot study. J Neuroinflammation 13: 157, 2016.

6. Goldschmidt E, Rasmussen J, Chabot JD, Gandhoke G, Luzzi E, Merlotti L, Proni R, Loresi M, Hamilton DK, Okonkwo DO, et al: The effect of vancomycin powder on human dural fibroblast culture and its implications for dural repair during spine surgery. J Neurosurg Spine 25: 665-670, 2016.

7. Blassmann U, Roehr AC, Frey OR, Vetter-Kerkhoff C, Thon N, Hope W, Briegel J and Huge V: Cerebrospinal fluid penetration of meropenem in neurocritical care patients with proven or suspected ventriculitis: a prospective observational study. Crit Care 20: 343, 2016.
8. Caughlin S, Maheshwari S, Agca Y, Agca C, Harris AJ, Jurcic K, Yeung KK, Cechetto DF and Whitehead SN: Membrane-lipid homeostasis in a prodromal rat model of Alzheimer's disease: Characteristic profiles in ganglioside distributions during aging detected using MALDI imaging mass spectrometry. Biochim Biophys Acta, Gen Subj 1862: 1327-1338, 2018.

9. Benktander J, Barone A, Johansson MM and Teneberg S: Helicobacter pylori SabA binding gangliosides of human stomach. Virulence 9: 738-751, 2018.

10. Sasaki N, Itakura Y and Toyoda M: Ganglioside GM1 contributes to extracellular/intracellular regulation of insulin resistance, impairment of insulin signaling and down-stream eNOS activation, in human aortic endothelial cells after short- or long-term exposure to TNFa. Oncotarget 9: 5562-5577, 2017.

11. Iwasawa T, Zhang P, Ohkawa Y, Momota H, WakabayashiT, Ohmi Y, Bhuiyan RH, Furukawa K and Furukawa K: Enhancement of malignant properties of human glioma cells by ganglioside GD3/GD2. Int J Oncol 52: 1255-1266, 2018.

12. Patet C, Suys T, Carteron L and Oddo M: Cerebral lactate metabolism after traumatic brain injury. Curr Neurol Neurosci Rep 16: 31, 2016.

13. Hackenberg $\mathrm{K}$ and Unterberg A: Traumatic brain injury. Nervenarzt 87: 203-214, quiz 215-216, 2016 (In German).

14. Duan M, Wang D, Wang J, Xiao X, Han L and Zhang F: A case report of intracranial infection caused by Shewanella putrefaciens. Neurol Sci 36: 625-629, 2015.

15. Cook AM, Arora S, Davis J and Pittman T: Augmented renal clearance of vancomycin and levetiracetam in a traumatic brain injury patient. Neurocrit Care 19: 210-214, 2013.

16. Huttner HB, Nagel S, Tognoni E, Köhrmann M, Jüttler E, Orakcioglu B, Schellinger PD, Schwab S and Bardutzky J: Intracerebral hemorrhage with severe ventricular involvement: Lumbar drainage for communicating hydrocephalus. Stroke 38: 183-187, 2007.

17. Wattanathum A, Chaoprasong C, Nunthapisud P, Chantaratchada S, Limpairojn N, Jatakanon A and Chanthadisai N: Communityacquired pneumonia in southeast Asia: The microbial differences between ambulatory and hospitalized patients. Chest 123: 1512-1519, 2003.

18. El Sayed Zaki M and Goda T: Clinico-pathological study of atypical pathogens in community-acquired pneumonia: A prospective study. J Infect Dev Ctries 3: 199-205, 2009.

19. Gaillat J, Flahault A, deBarbeyrac B, Orfila J, Portier H, Ducroix JP, Bébéar C and Mayaud C: Community epidemiology of Chlamydia and Mycoplasma pneumoniae in LRTI in France over 29 months. Eur J Epidemiol 20: 643-651, 2005.

20. Doder R, Canak G, Vukadinov J, Turkulov V and Sević S: Antibiotics in the treatment of bacterial infections of the central nervous system. Med Pregl 63 (Suppl 1): 22-26, 2010.

21. Kneen R, Solomon T and Appleton R: The role of lumbar puncture in suspected CNS infection - a disappearing skill? Arch Dis Child 87: 181-183, 2002.

22. Bao Y, Qiu B, Zeng H, Mo Y, Zhang N and Qi S: Combined intravenous and intrathecal vancomycin in treatment of patients with intracranial infections after craniotomy. Zhonghua Wei Zhong Bing Ji Jiu Yi Xue 28: 169-172, 2016 (In Chinese).

23. Lee K, Rho M, Yu M, Kwak J, Hong S, Kim J, Kim Y and Pai H: A case of recurrent meningitis caused by Rhodococcus species successfully treated with antibiotic treatment and intrathecal injection of vancomycin through an Ommaya reservoir. Infect Chemother 47: 183-189, 2015.

24. Chen K, Wu Y, Wang Q, Wang J, Li X, Zhao Z and Zhou J: The methodology and pharmacokinetics study of intraventricular administration of vancomycin in patients with intracranial infections after craniotomy. J Crit Care 30: 218.e1-218.e5, 2015.

25. Chen QH, Lin D, Yu QG and Zhou J: Efficacy of lumbar cistern drainage combined with intrathecal antibiotherapy for the treatment of ventriculo-subarachnoid infections following surgery for hypertensive intracerebral hemorrhage. Neurochirurgie 63: 13-16, 2017. 